\title{
Leiomiosarcoma de colon
}

\section{Primary Leiomyosarcoma of the Colon}

\author{
Ignacio Martín García1요 Rosario Vidal Tocino ${ }^{2}$ Bianca Prieto Hernández ${ }^{1}$ Elena Molina Terrón ${ }^{1}$ \\ Isabel Alonso Diego ${ }^{1}$ Sonia Francisca Pozo González ${ }^{1}$ Jesús Pinto Blázquez ${ }^{3}$
}

\author{
${ }^{1}$ Servicio de Radiodiagnóstico, Complejo Asistencial de Zamora, \\ Zamora, España \\ 2 Servicio de Oncología Médica, Hospital Universitario de Salamanca, \\ Salamanca, España \\ ${ }^{3}$ Servicio de Anatomía Patológica, Complejo Asistencial de Zamora, \\ Zamora, España
}

Rev Argent Radiol 2021;85:75-77.
Estimados editores,

El leiomiosarcoma de colon es una neoplasia muy rara del tracto gastrointestinal, aproximadamente entre 0,1 y $3 \%$ según series. Su origen es la capa muscular propia, las células musculares de la mucosa o de la pared de los vasos. Ocurre con mayor frecuencia entre la quinta y sexta década y la localización más frecuente es el estómago, seguido del intestino delgado, colon y recto, siendo en el colon más frecuente en el sigma y colon transverso., ${ }^{1,2}$

Compartimos un caso de leiomiosarcoma de colon que, por su rareza, merece ser reportado. El presente artículo tiene por objetivo revisar y destacar el aporte de la imagen abdominal en el diagnóstico del leiomiosarcoma de colon como neoplasia a tener en cuenta en el diagnóstico diferencial de las masas colónicas.

Se trata de una mujer de 50 años sin antecedentes de interés, que acudió al Servicio de Urgencias por molestias y sensación de masa en hipocondrio izquierdo. No presentó alteraciones reseñables en la analítica y a la exploración física mostró una masa palpable en hipocondrio/flanco izquierdos. Dada la historia clínica, se solicitó ecografía abdominal (-Fig. 1) que mostró una lesión de hasta $10 \mathrm{~cm}$ de eje mayor de aspecto polilobulado y anfractuoso, hipoecoica y con un área central con artefacto de reverberación por probable contenido aéreo. Ante esos hallazgos, se decidió realizar una tomografía computarizada (TC) (-Fig. 2) con contraste oral e
Address for correspondence Ignacio Martín García, PhD, Complejo Asistencial de Zamora, Av. de Requejo, 35, Zamora, España (e-mail: nachetemaga@hotmail.com).

intravenoso, apreciando una gran masa dependiente del ángulo esplénico del colon con crecimiento exofítico y ulceración con contenido de contraste oral. Con esos hallazgos, la lesión fue reportada como tumor del estroma gastrointestinal (GIST) de colon, como primera posibilidad, sin apreciar diseminación a distancia a ningún nivel.

Tras el diagnóstico por imagen, se propuso a la paciente para cirugía programada, realizando hemicolectomía derecha ampliada en la cual se extirpó una gran masa con crecimiento exofítico y área central ulcerada siendo resección macroscópica completa ( - Fig. 3). El estudio de anatomía patológica ( - Fig. 4) reportó una tumoración que crece hacia fuera y ulcera la mucosa, de consistencia pétrea y color blanquecino, tratándose de una tumoración sólida, densamente celular y que se extiende de forma transmural. Está constituida fundamentalmente por células fusiformes que forman haces separados por un estroma fibroso. Muestra células grandes, algunas con cierta apariencia epitelioide, observando en algunas ocasiones marcada anisocariosis. La inmuhistoquímica mostró negatividad para CD34, CD117 y DOG 1 y positividad para actina musculo liso. Dados esos hallazgos, se diagnosticó de leiomiosarcoma de colon grado 3 (G3).

Tras la cirugía no recibió tratamiento complementario de ningún tipo y mantiene revisiones sin evidencia de recidiva o received

April 16, 2020

accepted

September 11, 2020

published online

February 4, 2021
DOI https://doi.org/

10.1055/s-0040-1721343. ISSN 1852-9992.

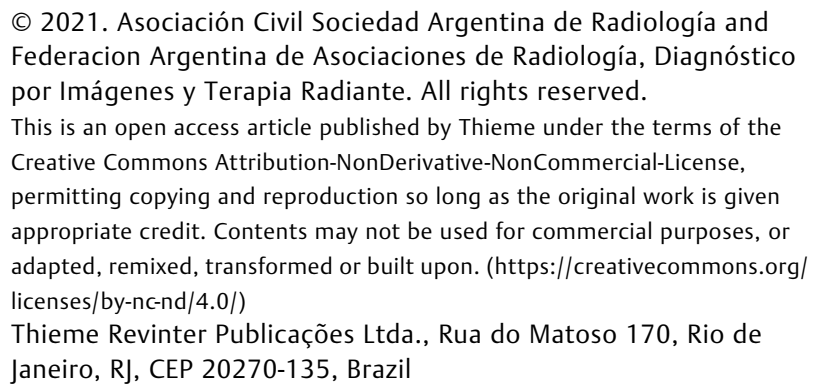

(C) 2021. Asociación Civil Sociedad Argentina de Radiología and Federacion Argentina de Asociaciones de Radiología, Diagnóstico por Imágenes y Terapia Radiante. All rights reserved.

This is an open access article published by Thieme under the terms of the Creative Commons Attribution-NonDerivative-NonCommercial-License, permitting copying and reproduction so long as the original work is given appropriate credit. Contents may not be used for commercial purposes, or adapted, remixed, transformed or built upon. (https://creativecommons.org/ licenses/by-nc-nd/4.0/)

Thieme Revinter Publicações Ltda., Rua do Matoso 170, Rio de Janeiro, RJ, CEP 20270-135, Brazil 


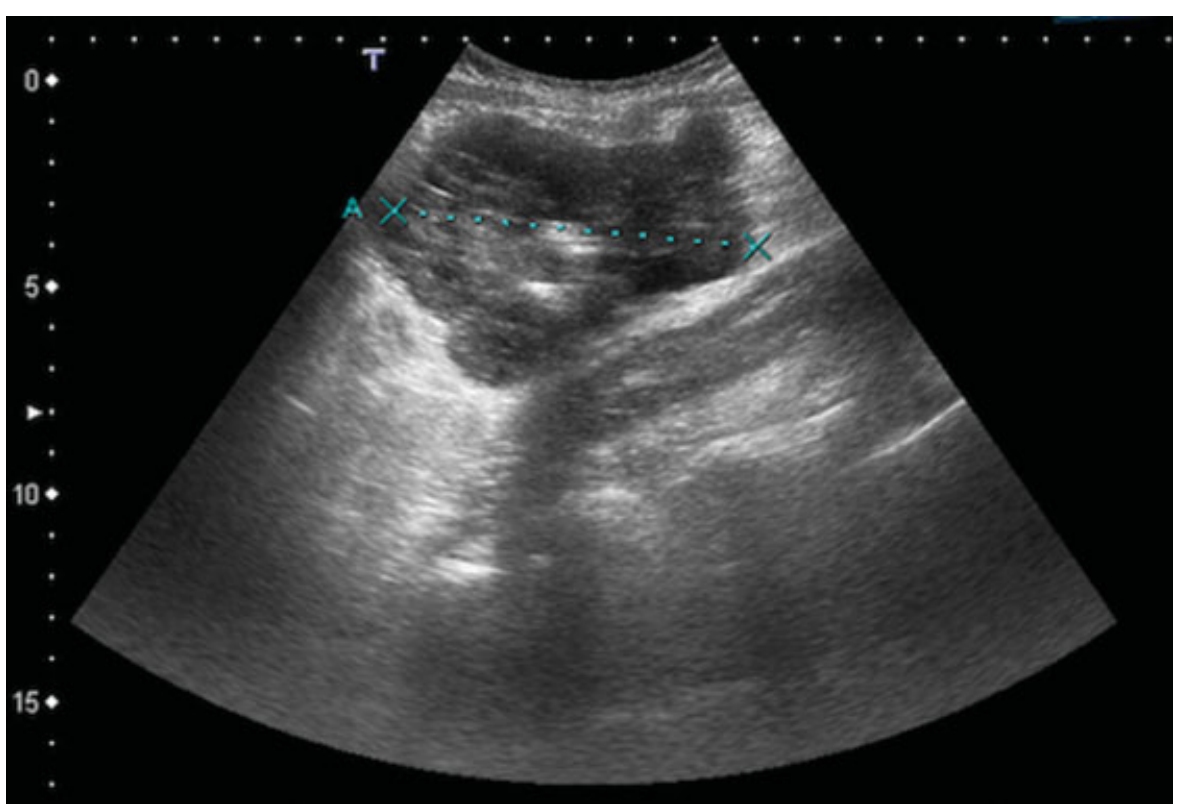

Fig. 1 Ecografía abdominal a nivel de hipocondrio izquierdo. Coincidiendo con la masa palpable, se objetiva una lesión de hasta $10 \mathrm{~cm}$ de eje mayor, hipoecoica y de contornos anfractuosos con un área central de artefacto de reverberación por probable contenido aéreo.

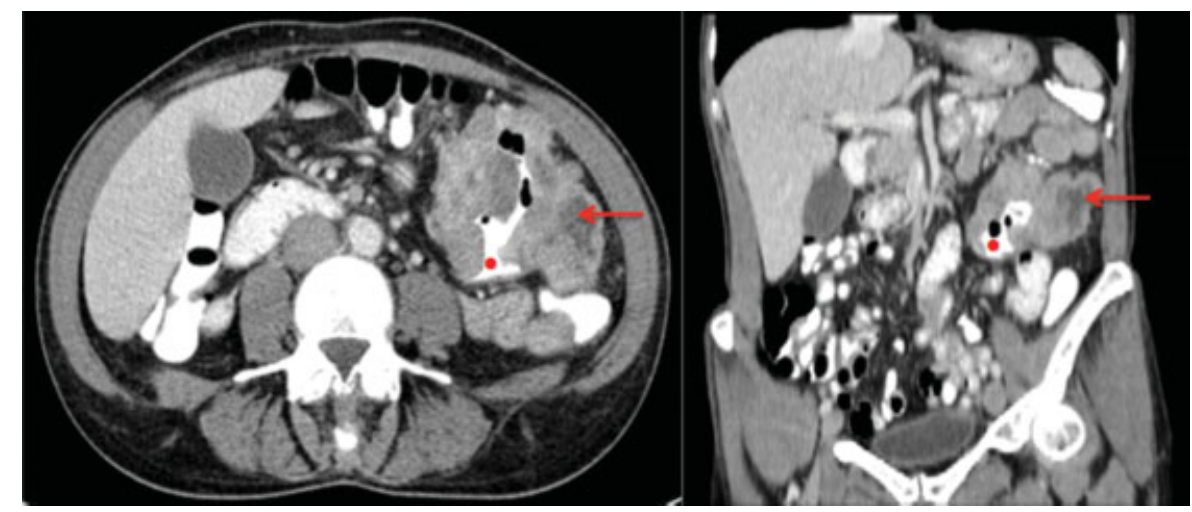

Fig. 2 TC con contraste oral e intravenoso, plano axial (izquierda) y plano coronal (derecha). Luz intestinal (punto rojo) y tumoración (flecha roja). Se aprecia una gran masa heterogénea dependiente del ángulo esplénico del colon con crecimiento exofítico hacia cavidad la abdominal y ulceración de la lesión con contenido de contraste oral. Esa lesión presenta contornos irregulares y captación heterogénea de contraste.

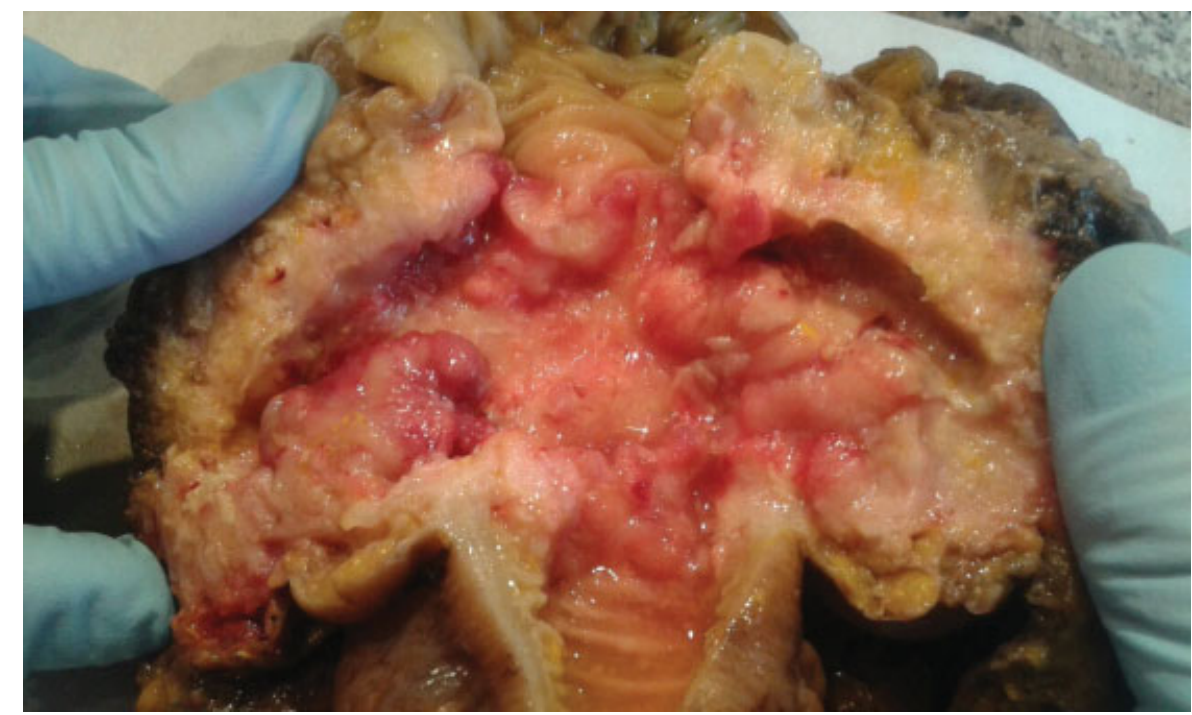

Fig. 3 Pieza quirúrgica de colectomía. En la parte central de la imagen se aprecia la luz del colon y cómo las manos separan la tumoración exofítica y ulcerada. 

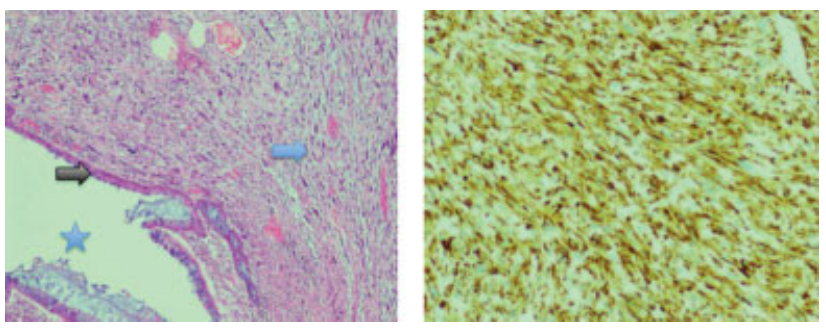

Fig. 4 Imagen histológica con tinción de hematoxilina eosina (magnificación 100x) (izquierda) e imagen de la técnica inmunohistoquímica actina musculo liso (magnificación x 10) (derecha), en la que se aprecia positividad de células de músculo liso neoplásicas. Se aprecia la luz intestinal (estrella) y una tumoración en pared intestinal, densamente celular, formada por células epitelioides y fusiformes (flecha azul). La mucosa intestinal no muestra alteraciones reseñables (flecha negra).

metástasis, con un intervalo libre de enfermedad de 45 meses.

Los síntomas del leiomiosarcoma de colon pueden ser inespecíficos, como dolor abdominal, pérdida de peso y alteración del ritmo intestinal. ${ }^{1,3}$ La diseminación a distancia suele ser hematógena a pulmón, peritoneo e hígado, siendo muy rara la enfermedad ganglionar. ${ }^{4}$

Dada la diferencia en el tratamiento y pronóstico, es de gran importancia diferenciar esos tumores de otro tipo de sarcomas, como los GIST. Por ello, es clave el estudio inmunohistoquímico, en el GIST se encuentra positividad para CD34, CD117 y DOG1, mientras que en el leiomiosarcoma ellos son negativos $\mathrm{y}$ positivos para desmina, alfa SMA, vimentina y h-caldesmon. ${ }^{5,6}$

El tratamiento complementario a la cirugía radical es controvertido. Algunos estudios muestran beneficio marginal con quimioterapia y/o radioterapia (RT), sobre todo en tumores de alto grado, profundos y mayores de $5 \mathrm{~cm}$, o con márgenes afectos en caso de RT. Hay que tener en cuenta que el leiomiosarcoma es relativamente insensible a la quimioterapia. ${ }^{7}$ El caso que nos ocupa presentó una localización extremadamente infrecuente, con escasa o nula representación en los ensayos clínicos y donde la cirugía radical es posible, de manera que, tras su valoración multidisciplinar, se decidió realizar seguimiento.

\section{Responsabilidades éticas}

Protección de personas y animales. Los autores declaran que para esta investigación no se han realizado experimentos en seres humanos ni en animales.

Confidencialidad de los datos. Los autores declaran que en este artículo no aparecen datos de pacientes.

Derecho a la privacidad y consentimiento informado. Los autores declaran que en este artículo no aparecen datos de pacientes.

\section{Conflicto de intereses}

Los autores del trabajo declaran no tener ningún conflicto de intereses.

\section{Referencias}

1 Yaren A, Değirmencioğlu S, Callı Demirkan N, Gökçen Demiray A, Taşköylü B, Doğu GG. Primary mesenchymal tumors of the colon: a report of three cases. Turk J Gastroenterol. 2014;25(03): 314-318

2 Singh P, Bello B, Weber C, Umanskiy K. Rectal leiomyosarcoma in association with ulcerative colitis: a rare condition with an unusual presentation. Int J Colorectal Dis. 2014;29(07):887-888

3 Iwasa K, Taniguchi K, Noguchi M, Yamashita H, Kitagawa M. Leiomyosarcoma of the colon presenting as acute suppurative peritonitis. Surg Today. 1997;27(04):337-344

4 Faraj W, El-Kehdy J, Nounou GE, Deeba S, Fakih H, Jabbour M, et al. Liver resection for metastatic colorectal leiomyosarcoma: a single center experience. J Gastrointest Oncol. 2015;6(05):E70-E76

5 Svarvar C, Böhling T, Berlin O, Gustafson P, Folleras G, Bjerkehagen B, et al; Scandinavian Sarcoma Group Leiomyosarcoma Working Group. Clinical course of nonvisceral soft tissue leiomyosarcoma in 225 patients from the Scandinavian Sarcoma Group. Cancer. 2007;109(02):282-291

6 Katz SC, DeMatteo RP. Gastrointestinal stromal tumors and leiomyosarcomas. J Surg Oncol. 2008;97(04):350-359

7 Singer S, Tap WD, Kirsch DG, Crago AM. Soft tissue sarcoma. In: DeVita VT, Lawrence TS, Rosenberg SA, editors. DeVita, Hellman, and Rosenberg's Cancer: Principles \& Practice of Oncology, 11th ed. Philadelphia, PA: Wolters Kluwer; 2019:1400-1450 